\title{
High Gain UWB Four Elements Antenna Array for C-Band and X-Band Application
}

\author{
Tamer Gaber Abouelnaga1, Mazhar Basyouni Tayel², Asmaa Fereg Desouky³ \\ ${ }^{1}$ Microstrip Circuits Department, Electronic Research Institute ERI, El Nozha El Gadida, Cairo, Egypt \\ ${ }^{2}$ Electrical Department, Faculty of Engineering, Alexandria University, Alexandria, Egypt \\ ${ }^{3}$ Communication Department, Higher Institute of Engineering and Technology HIET, Kafr Elsheikh, Egypt \\ Email: tamer@eri.sci.eg,profbasyouni@gmail.com, asmaa.fereg@gmail.com
}

How to cite this paper: Abouelnaga, T.G. Tayel, M.B. and Desouky, A.F. (2020) High Gain UWB Four Elements Antenna Array for C-Band and X-Band Application. Open Journal of Antennas and Propagation, 8 , 19-29.

https://doi.org/10.4236/ojapr.2020.82002

Received: June 5, 2020

Accepted: June 27, 2020

Published: June 30, 2020

Copyright () 2020 by author(s) and Scientific Research Publishing Inc. This work is licensed under the Creative Commons Attribution International License (CC BY 4.0).

http://creativecommons.org/licenses/by/4.0/

\begin{abstract}
The C-band is allocated for commercial telecommunications via satellites. Amateur satellite operations in the frequency range 5.830 to $5.850 \mathrm{GHz}$ for down-links and 5.650 to $5.670 \mathrm{GHz}$ for up-links are allowed by International Telecommunication Union. The X-band is used for terrestrial broadband communication, radar applications, and portions of the X-band are assigned for deep space telecommunications. In this paper, a design of $4 \times 1$ Ultra Wide Band (UWB) antenna array for C-band and X-band applications is introduced. Metamaterial sixteen-unit cells are incorporated into each antenna element for radiation characteristics enhancement purposes. Permeability and permittivity of metamaterial unit cells are obtained all over the operating bandwidth. UWB unequal power divider is used to feed the proposed four elements antenna array based on Chebyshev excitation method. The proposed antenna has a suitable 3 $\mathrm{dB}$ beam width and gains all over the operating bandwidth which extends from $5.6 \mathrm{GHz}$ to $10.9 \mathrm{GHz}$. The proposed antenna covers $60 \%$ and $72.5 \%$ of the C-band and X-band, respectively. The proposed antenna is fabricated, measured, and good agreement is obtained between simulated and measured results. The obtained performance ensures the suitability of the proposed antenna array for C-band and X-band applications.
\end{abstract}

\section{Keywords}

C-Band, X-Band, Metamaterial, Antenna Array, UWB

\section{Introduction}

The $\mathrm{C}$ and $\mathrm{X}$-bands are allocated by the Institute of Electrical and Electronics Engineers (IEEE) to be extended from 4 to $8 \mathrm{GHz}$ and from 8.0 to $12 \mathrm{GHz}$, respectively. The C-band is used in many satellite communications, weather radar systems, some Wi-Fi devices, and some surveillance systems. Amateur satellite operations in the frequency range 5.830 to $5.850 \mathrm{GHz}$ for down-links and 5.650 to $5.670 \mathrm{GHz}$ for up-links are allowed by International Telecommunication Union. The X-band is 
used in terrestrial broadband communication and radar applications. In many countries, X-band segment which extends from 10.15 to $10.7 \mathrm{GHz}$ is used for terrestrial broadband communication. Deep space telecommunications use portions of the $\mathrm{X}$ band. The antenna is the most important part of any wireless communication system. Due to small size, light-weight, cost-effectiveness, easy to fabricate and integrate into any circuit, microstrip antennas MPAs are the most candidates for applications, such as spaceborne systems and radar or satellite systems [1]. The proposed antenna design is suitable for the application of the C-band and X-band application. C-band and X-band are allocated by the Institute of Electrical and Electronics Engineers (IEEE) for a portion of the electromagnetic spectrum ranging from 4.0 to $8.0 \mathrm{GHz}$ and 8.0 to $12 \mathrm{GHz}$, respectively. To cover both $\mathrm{C}$-band and $\mathrm{X}$-band frequency spectrum, $4 \times 1$ UWB high gain antenna array for C-band and X-band UWB is introduced. Many researchers have been discussed with various UWB antenna structures [2]-[12]. Table 1 shows many UWB antennas and a comparison among them. One can notice that the widest bandwidth of $11.95 \mathrm{GHz}$ was introduced by [9] but with a maximum gain of $3.5 \mathrm{dBi}$. The highest gain was introduced by [7] but with a bandwidth of $1.5 \mathrm{GHz}$.

All the aforementioned researches suffer from low gain value for a single element antenna which is a very important parameter for receiver detection system. This paper introduces an ultra-wide band (UWB) high gain antenna array through incorporating metamaterial cells with a single element and uses Chebyshev elements excitation method for the four elements antenna array. Since metamaterial cell is a frequency-dependent structure, the gain will be enhanced only at a

Table 1. Comparison amoung UWB antennas.

\begin{tabular}{ccccc}
\hline Ref. & Antenna size & BW $(\mathrm{GHz})$ & Gain $(\mathrm{dBi})$ & $3 \mathrm{~dB}$ BW $\left(\right.$ degree $\left.^{\circ}\right)$ \\
\hline$[2]$ & $34.6 \times 21.5$ & $3.28-6.95$ & 4.5 & $78^{\circ}$ \\
{$[3]$} & $25 \times 25$ & $3.1-10$ & - & $60^{\circ}$ \\
{$[4]$} & $40 \times 26$ & $3.1-10.6$ & - & - \\
{$[5]$} & $23 \times 29$ & $4.5-10$ & 5 & - \\
{$[6]$} & $19 \times 19$ & $2-8$ & - & $80^{\circ}$ \\
{$[7]$} & $30 \times 30$ & $0.5-2$ & 6.3 & $78^{\circ}$ \\
{$[8]$} & $42.8 \times 42.8$ & $3.1-10.6$ & 5.5 & - \\
{$[9]$} & $19.3 \times 27.7$ & $3.05-15$ & 3.5 & $90^{\circ}$ \\
{$[10]$} & $28 \times 32$ & $5.3-8.5$ & 5 & $70^{\circ}$ \\
{$[11]$} & $16 \times 21$ & $3.4-12.5$ & 4.5 & $85^{\circ}$ \\
{$[12]$} & $75 \times 75$ & $1.15-4.4$ & 2.9 & $60^{\circ}$ \\
\hline
\end{tabular}

portion of the operating frequency. Firstly, a single UWB antenna element with 16 metamaterial cells is designed and analyzed. Secondly, UWB unequal power divider is used to feed the antenna array based on Chebyshev elements excitation. Four elements Chebyshev UWB antenna array with reflector is proposed. Finally, 
the proposed antenna array reflection coefficient is measured and compared with its simulated counterpart. The metamaterial structure is chosen carefully for gain enhancement at a narrow frequency band in the UWB of the proposed array. The MTML unit cell and the antenna array are simulated using CST Microwave Studio 2014.

\section{Proposed Antenna Array Design and Configuration}

In [13], a transition from coaxial-to-coplanar waveguide (CPW) was presented. This transition is important for avoiding air gap between antennas and patient's skin which may cause power losses. In this paper, this transition is used in developing an UWB antenna for detection process. Sections 2.1, 2.2 and 2.3 present the proposed antenna array structure stages.

\subsection{Antenna Element}

The proposed antenna structure is shown in Figure 1(a). It consists of the common coplanar fed slot antenna [14] as radiator and the proposed transition [13]. The FR4 dielectric constant of 4.6 and height $1.53 \mathrm{~mm}$ considered as antenna substrate. The substrate size of the radiator is $49 \mathrm{~mm} \times 30 \mathrm{~mm} \times 1.53 \mathrm{~mm}$. Figure 1(b) shows the proposed antenna optimized dimensions shown in Table 2. Figure 2(a) shows the simulated reflection coefficient of the proposed antenna, extended from $(3.6 \mathrm{GHz}-10 \mathrm{GHz})$. Figure 2 (b) shows that a maximum gain of $4.5 \mathrm{~dB}$ is obtained at $8 \mathrm{GHz}$.

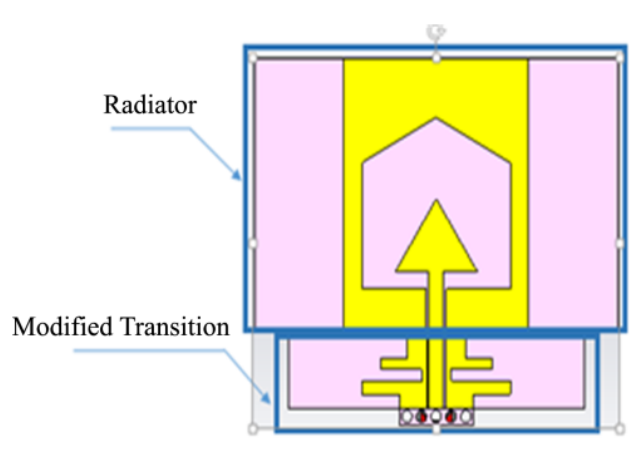

(a)

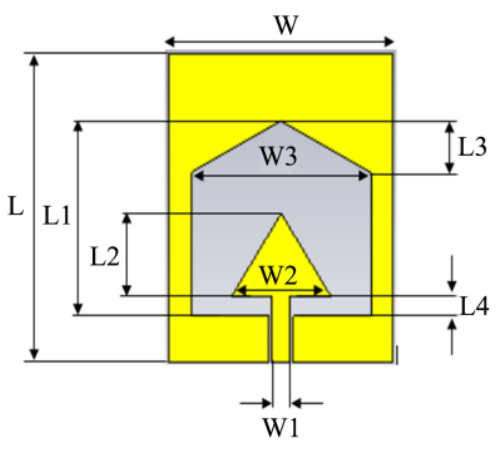

(b)

Figure 1. (a) The proposed antenna structure (Transformation and radiator); (b) The proposed antenna dimensions.

Table 2. Proposed antenna parameters value in $\mathrm{mm}$.

\begin{tabular}{ccccccccc}
\hline Parameter & W & W1 & W2 & W3 & L & L1 & L2 & L3 \\
\hline Dimension (mm) & 25 & 2.023 & 11 & 20 & 30 & 19 & 8 & 5 \\
\hline
\end{tabular}




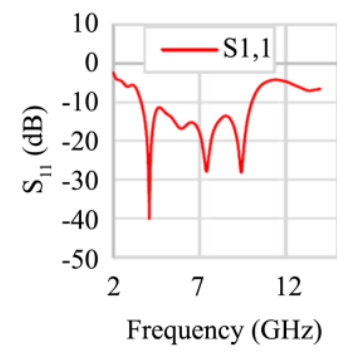

(a)

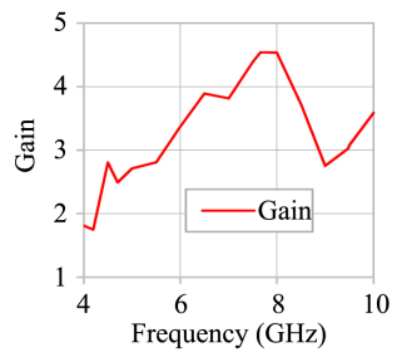

(b)

Figure 2. (a) The simulated Reflection coffecient of the proposed antenna; (b) The simulatedgain of the proposed antenna.

\subsection{Metamaterial Cells}

Metamaterial cell is an integration of a Capacitive Loaded Strip (CLS), modified split ring resonator (SRR) and wire, to achieve a negative electrical permittivity and a negative magnetic permeability [9]. This results in a spectacular negative refractive index that enables amplification of the radiated power of the proposed antenna. A low-cost FR4 substrate material is used to design and print this proposed cell.

The overall structure size is $10 \mathrm{~mm} \times 7.29 \mathrm{~mm} \times 1.53 \mathrm{~mm}$. The metamaterial unit cell is based on an SRR structure. The SRR structure is made of two octagonal loops. A smaller octagonal loop within a bigger octagonal one. The smaller one with gaps in the middle of the octagonal shape. These gaps make a capacitance which controls the resonant characteristic of the metamaterial structure. The CLSs which act as electric dipole are I-shaped striplines that mimic long metallic wires. The combined structure (SRR and CLSs) allows for simultaneous electric and magnetic resonance because the SRR resonates with a perpendicular magnetic field and the CLSs resonates through a parallel electric field. Figure 3(a) shows the simulation geometry of the unit cell. The MTML unit cell is simulated using CST Microwave Studio. The structure used for testing was located between two waveguide ports situated on each side of the x-axis. An electromagnetic wave was excited along the $\mathrm{x}$-axis. A perfectly conducting electrical boundary condition was applied along the walls perpendicular to the y-axis and a perfectly conducting magnetic boundary was applied to the walls perpendicular to z-axis. The normalized impedance is matched to $50 \Omega$. Figure 3(b) shows the octagonal metamaterial parameters. Table 3 shows the value of the proposed MTML dimensions.

The S-parameters are shown in Figure 4. The Nicolson-Ross-Weir approach [15] [16] was used to extract the constitutive effective parameters from $S_{11}$ and $S_{21}$ including the relative permeability $\mu_{r}$, the relative permittivity $\varepsilon_{r}$ and their refractive index $n_{r}$ as follow:

$$
\begin{aligned}
& \varepsilon_{r}=\frac{2}{j k_{o} d} * \frac{1-V_{1}}{1+V_{1}} \\
& \mu_{r}=\frac{2}{j k_{o} d} * \frac{1-V_{2}}{1+V_{2}}
\end{aligned}
$$




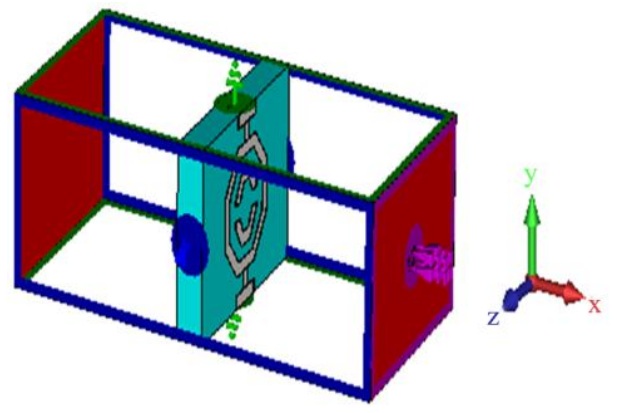

(a)

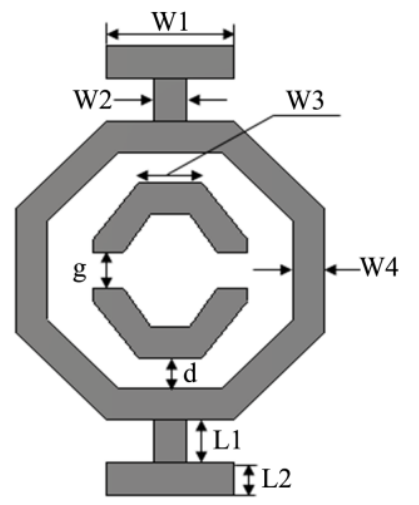

(b)

Figure 3. (a) The proposed structure of the MTML unit cell; (b) The proposed MTML structure specification.

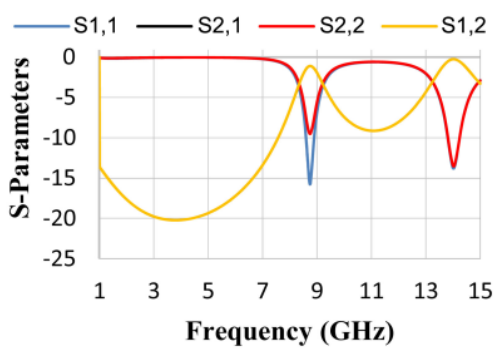

Figure 4. The magnitude of the S-parameters for the proposed MTML unit cell.

Table 3. The design parameters of the proposed unit cell.

\begin{tabular}{ccccccccc}
\hline Parameter & W1 & W2 & W3 & W4 & L1 & L2 & $g$ & $d$ \\
\hline Dimension (mm) & 2 & 0.5 & 1 & 0.5 & 0.7 & 0.52 & 0.6 & 0.5 \\
\hline \multicolumn{1}{c}{} & \\
$n_{r}=\sqrt{E_{r} \mu_{r}}$ & \\
$V_{1}=S_{21}+S_{11}$ \\
$V_{2}=S_{21}-S_{11}$
\end{tabular}

where: $k_{o}=\omega / C, d=$ slab thickness and $C=$ speed of light. A Matlab code is built to extract the relative permittivity $\varepsilon_{r}$ and relative permeability $\mu_{r}$ curves from the S-parameters. Figure 5 shows the proposed MTML permittivity $\varepsilon_{r}$ and permeability $\mu_{r}$. Table 4 shows the values of permittivity and permeability in the negative frequency zone.

\subsection{Antenna Loaded with MTML}

Figure 6(a) shows the antenna where sixteen MTML cells are placed along $\mathrm{x}$ and $y$-axis of the antenna substrate. These cells are in the direction of the antenna radiation to enhance the antenna directivity. The antenna is printed on FR4 material. The overall antenna dimensions are $49 \mathrm{~mm} \times 38.7 \mathrm{~mm} \times 1.53 \mathrm{~mm}$.

Figure 6(b) shows the simulated Reflection coefficient of the proposed antenna covering frequency band from $(3.9 \mathrm{GHz}-10 \mathrm{GHz})$. Figure 7 shows a 


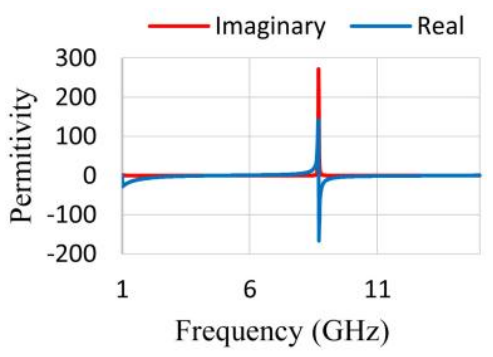

(a)

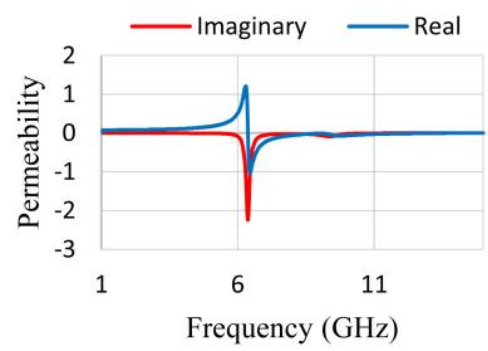

(b)

Figure 5. The proposed unit cell (a) permittivity $\varepsilon_{r}$ and (b) permeability $\mu_{r}$.

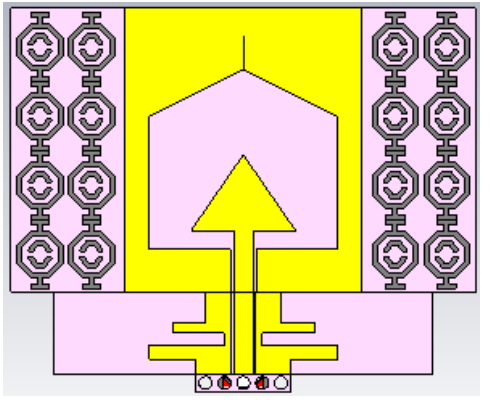

(a)

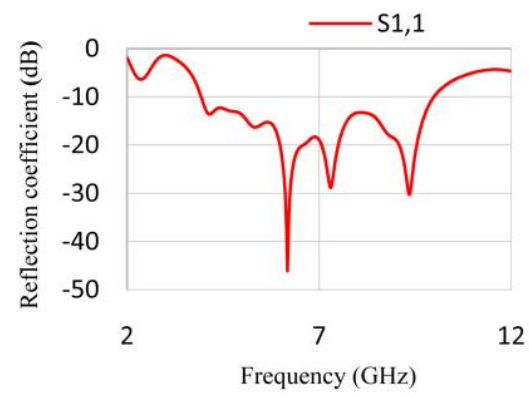

(b)

Figure 6. (a) The proposed antenna with proposed MTML unit cell; (b) The simulated Reflection coffecient of the proposed antenna with MTML.

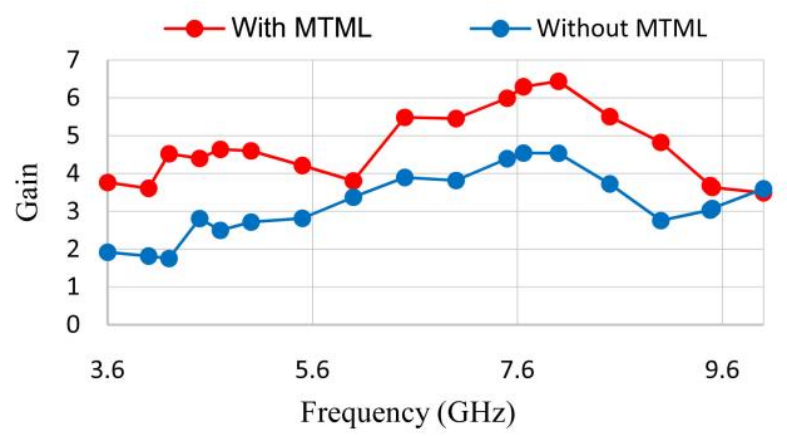

Figure 7. The gain values of the proposed antenna without metamaterial and with MTML.

Table 4. The permeability and permittivity in the negative frequency zone.

\begin{tabular}{cc}
\hline Parameter & Negative Frequency Zone $(\mathrm{GHz})$ \\
\hline Permittivity, $\varepsilon_{r}$ & $1-6.5,8.7-12.5$ \\
Permeability, $\mu_{r}$ & $6.5-9,9.2-12$ \\
\hline
\end{tabular}

comparison between the gain value of the proposed antenna with and without metamaterial cells. It is noticed that the incorporation of metamaterial cells shows a gain enhancement of about $2 \mathrm{~dB}$. Figure 8 shows the 3D radiation pattern of the antenna, one noticed that the antenna has an omnidirectional radiation pattern. Also, the beam width (angular width) is $70.3^{\circ}$. Both results are not 

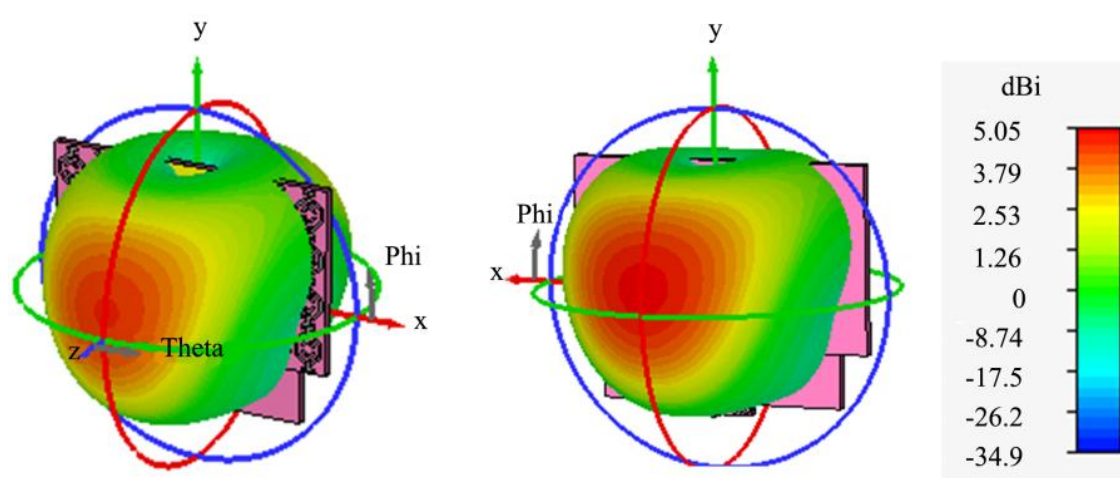

Figure 8. The radiation pattern of proposed antenna with metamaterial from front side and back side.

good enough for C-band Application process. The goal is to have an antenna with a narrow $3 \mathrm{~dB}$ beamwidth. So, an antenna array will be used. Figure 9 shows the radiation pattern in $\mathrm{x}-\mathrm{z}$ plane.

\subsection{Antenna Array}

The proposed antenna element with metamaterial 16 cells is used to design a $4 \times 1$ antenna array. The proposed antenna array operates at UWB rang extends from $5.6 \mathrm{GHz}-10.9 \mathrm{GHz}$. Resonant frequencies at $3.08 \mathrm{GHz}, 4.12 \mathrm{GHz}$ and $5.16 \mathrm{GHz}$ are occurred. Figure 10 shows the structure of the $4 \times 1$ antenna array with feeding network based on UWB Wilkinson unequal power divider which was presented in [17]. Figure 11 shows the fabricated antenna array where a reflector is placed at back side. The reflector size is $230 \mathrm{~mm} \times 60 \mathrm{~mm}$ and is placed at $10 \mathrm{~mm}$ from the antenna substrate. The reflection coefficient of the fabricated antenna array and its simulated counterpart are shown in Figure 12. Figure 13 shows the comparison between the uniform linear array (ULA) gain without MTML and with MTML. It is noticed that the incorporation of metamaterial cells shows a gain enhancement of about $3 \mathrm{~dB}$ from $9 \mathrm{GHz}$ to $10.5 \mathrm{GHz}$ and about $2 \mathrm{~dB}$ from 5.8 to 8.5 GHz. 3D radiation pattern of the proposed antenna array is shown in Figure 14 where directivity of $14.5 \mathrm{dBi}$ is obtained at $4.12 \mathrm{GHz}$. Figure 15 shows the XZ plane of the radiation pattern where a side loop level of $-11.2 \mathrm{dBi}$ and half power beam width $=17.7^{\circ}$ are obtained. Table 5 shows a comparison between antenna parameters of single element, single element with metamaterial and $4 \times 1$ antenna array.

\section{Conclusion}

A design and implementation of a UWB metamaterial antenna array was introduced for C-band and X band applications. The antenna array bandwidth extends from $5.6 \mathrm{GHz}$ to $10.9 \mathrm{GHz}$. The introduction of metamaterial cells enhanced the gain of a single element antenna of about $2 \mathrm{~dB}$. The proposed antenna array of $4 \times$ 1 elements achieved high directivity, high gain and reasonable beam width at different frequency bands. Good agreement was obtained between 


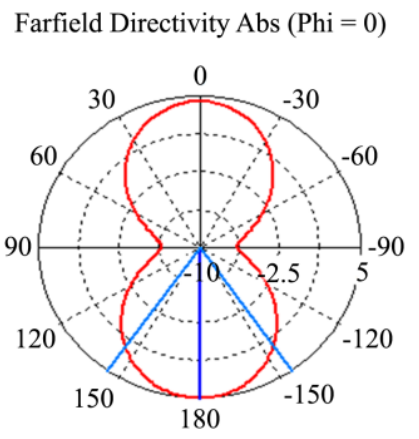

Theta/Degree vs. dBi
— farfield $(\mathrm{f}=5)[1]$

Frequency $=5$

Main lobe magnitude $=4.91 \mathrm{dBi}$

Main lobe direction $=180.0 \mathrm{deg}$.

Angular width $(3 \mathrm{~dB})=70.3 \mathrm{deg}$.

Figure 9. The radiation pattern in $\mathrm{x}-\mathrm{z}$ plane.

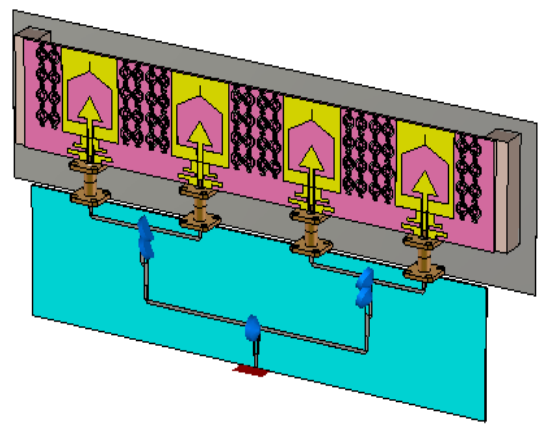

Figure 10. The structure of the $4 \times 1$ antenna array with feeding network based on $\lambda / 4$ transformer.

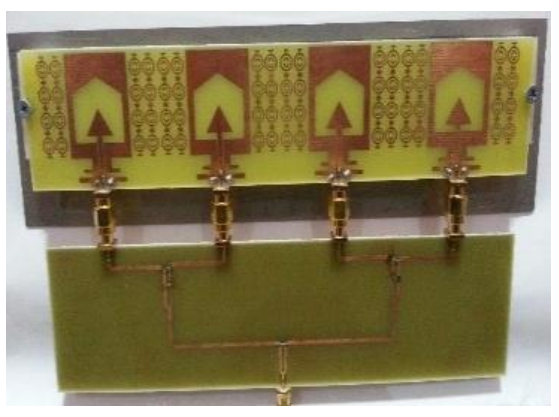

(a)

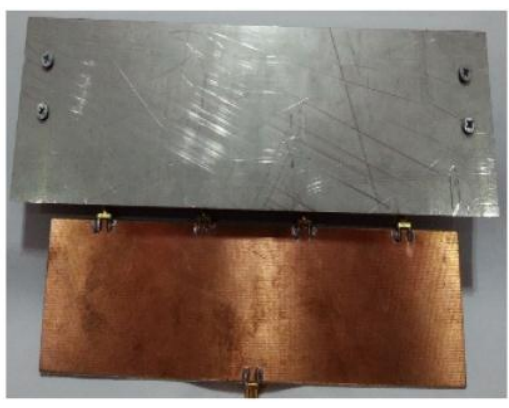

(b)

Figure 11. The fabricated antenna array (a) front side and (b) back side.

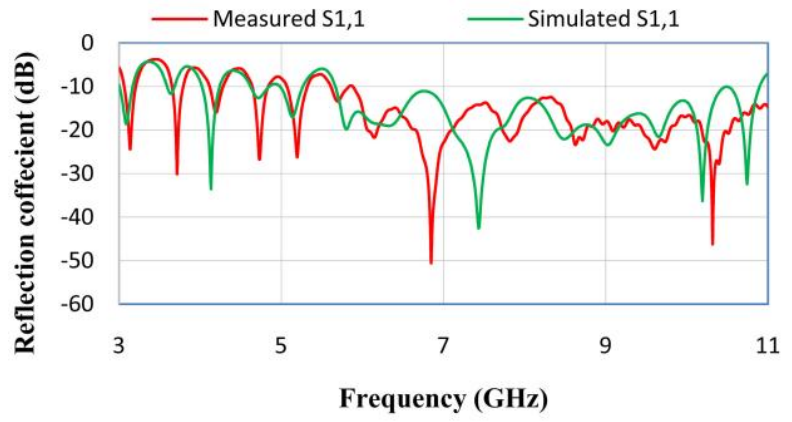

Figure 12. The reflection coefficient of the fabricated antenna array and simulated antenna array. 


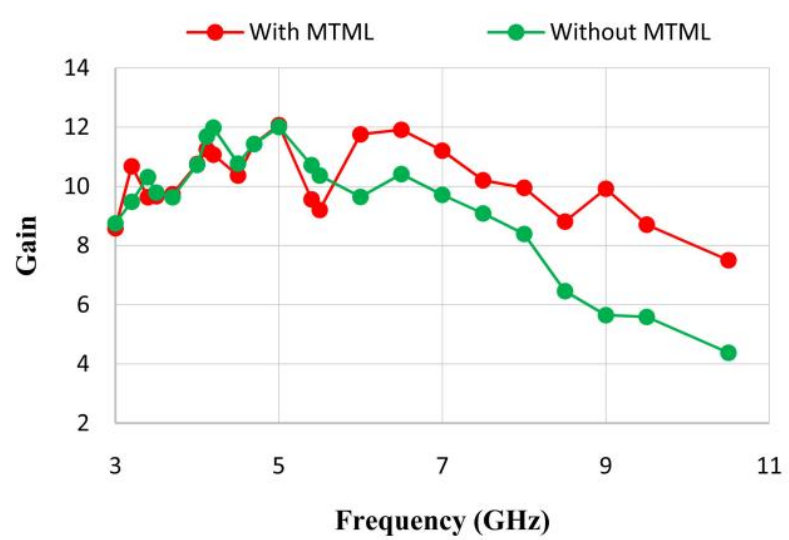

Figure 13. The gain values of the proposed antenna array without MTML and with MTML.

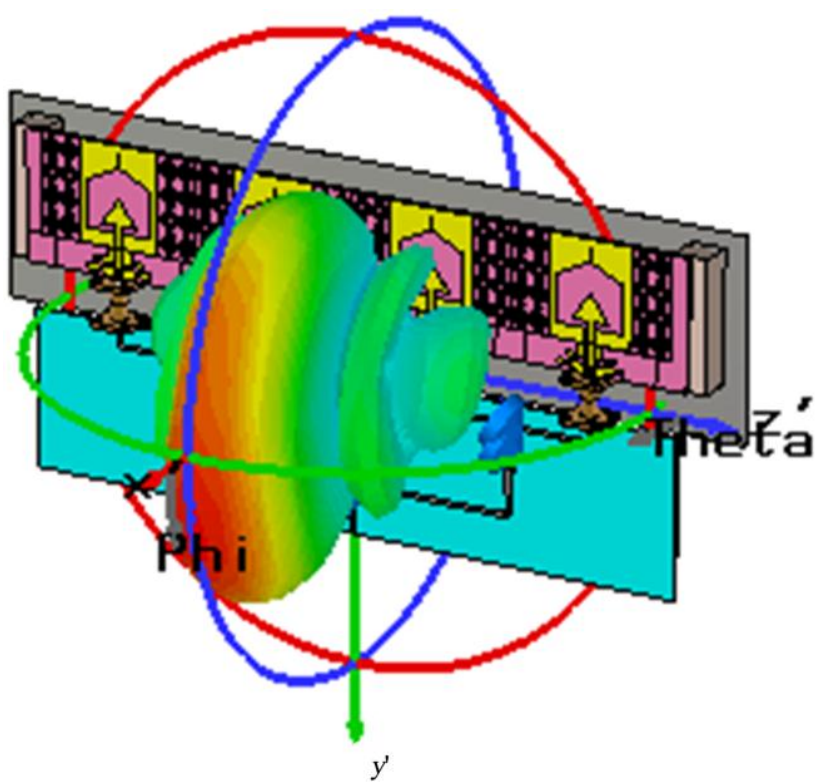

$\mathrm{dB}$

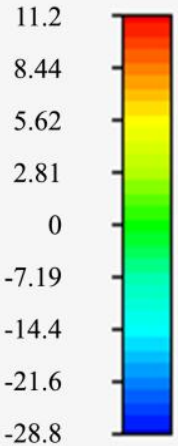

Figure 14. The 3D radiation pattern of the proposed antenna array.

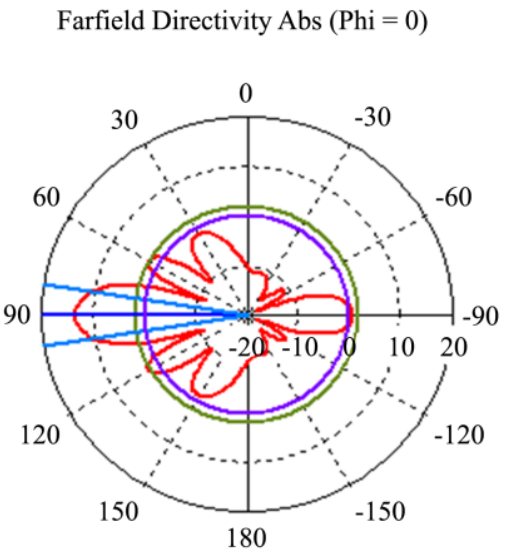

Theta/Degree vs. dBi farfield $(\mathrm{f}=4.12)[1]$

Frequency $=4.12$

Main lobe magnitude $=13.2 \mathrm{dBi}$

Main lobe direction $=90.0 \mathrm{deg}$.

Angular width $(3 \mathrm{~dB})=17.7 \mathrm{deg}$.

Side lobe level $=-11.2 \mathrm{~dB}$

Figure 15. The XZ plane of the radiation pattern.

Table 5. A comparison of antenna parameters between single element with MTML and array. 


\begin{tabular}{ccccc}
\hline & Resonance Frequency & Bandwidth GHz & $3 \mathrm{~dB}$ Beam width & Gain dB \\
\hline Single element & $6.1 \mathrm{GHz}$ & & 56 & \\
with MTML & $7.3 \mathrm{GHz}$ & $(3.9-10)$ & 75.6 & $(3.6-6.5)$ \\
& $9.3 \mathrm{GHz}$ & & 122 & \\
& $4.12 \mathrm{GHz}$ & & 17.7 & \\
Array with MTML & $6.4 \mathrm{GHz}$ & $(5.6-10.9)$ & 11.6 & $(10-12)$ \\
& $7.4 \mathrm{GHz}$ & & 9.6 & \\
& $8.5 \mathrm{GHz}$ & & 10.1 & \\
\hline
\end{tabular}

simulated and measured results. The main problem is the frequency-dependent nature of the metamaterial cell which will enhance the gain only at the portion of the frequency band. This issue will be addressed as a future work to be overcome to enhance the gain all over the operating UWB frequency band.

\section{Conflicts of Interest}

The authors declare no conflicts of interest regarding the publication of this paper.

\section{References}

[1] Balanis, C.A. (2016) Antenna Theory: Analysis and Design. John Wiley \& Sons, Hoboken.

[2] Shan, X. and Shen, Z. (2019) Miniaturized UHF/UWB Tag Antenna for Indoor Positioning Systems. IEEE Antennas and Wireless Propagation Letters, 18, 2453-2457. https://doi.org/10.1109/LAWP.2019.2938808

[3] Benavides, J.B., Lituma, R.A., Chasi, P.A. and Guerrero, L.F. (2018) A Novel Modified Hexagonal Shaped Fractal Antenna with Multi Band Notch Characteristics for UWB Applications. 2018 IEEE-APS Topical Conference on Antennas and Propagation in Wireless Communications (APWC), Cartagena des Indias, 10-14 September 2018, 830-833. https://doi.org/10.1109/APWC.2018.8503774

[4] Jiao, X., Wang, J. and Ying, Z. (2019) A Compact Two-Port Integrated UWB and Frequency Reconfigurable Antenna System for Cognitive Radio Application. 2019 IEEE MTT-S International Wireless Symposium (IWS), Guangzhou, 19-22 May 2019, 1-3. https://doi.org/10.1109/IEEE-IWS.2019.8804119

[5] Klemm, M., Craddock, I.J., Leendertz, J.A., Preece, A. and Benjamin, R. (2009) Radar-Based Breast Cancer Detection Using a Hemispherical Antenna Array-Experimental Results. IEEE Transactions on Antennas and Propagation, 57, 1692-1704. https://doi.org/10.1109/TAP.2009.2019856

[6] Wang, Y., Fathy, A.E. and Mahfouz, M.R. (2011) Novel Compact Tapered Microstrip Slot Antenna for Microwave Breast Imaging. 2011 IEEE International Symposium on Antennas and Propagation (APSURSI), Spokane, 3-8 July 2011, 2119-2122.

[7] Li, X., Jalilvand, M., Sit, Y.L. and Zwick, T. (2014) A Compact Double-Layer On-Body Matched Bowtie Antenna for Medical Diagnosis. IEEE Transactions on Antennas and Propagation, 62, 1808-1816. https://doi.org/10.1109/TAP.2013.2297158

[8] Bah, M.H., Hong, J., Jamro, D.A., Liang, J.J. and Kponou, E.A. (2014) Vivaldi Antenna and Breast Phantom Design for Breast Cancer Imaging. 2014 7th International Conference on Biomedical Engineering and Informatics, Dalian, 14-16 October 2014, 90-93. https://doi.org/10.1109/BMEI.2014.7002749

[9] Islam, M., Islam, M.T., Faruque, M.R.I., Samsuzzaman, M., Misran, N. and Arshad, H. (2015) Microwave Imaging Sensor Using Compact Metamaterial UWB Antenna with a High Correlation Factor. Materials, 8, 4631-4651. 
https://doi.org/10.3390/ma8084631

[10] Li, L.W., Li, Y.N., Yeo, T.S., Mosig, J.R. and Martin, O.J. (2010) A Broadband and High-Gain Metamaterial Microstrip Antenna. Applied Physics Letters, 96, Article ID: 164101. https://doi.org/10.1063/1.3396984

[11] Islam, M., Islam, M.T., Samsuzzaman, M., Faruque, M.R.I., Misran, N. and Mansor, M.F. (2015) A Miniaturized Antenna with Negative Index Metamaterial Based on Modified SRR and CLS Unit Cell for UWB Microwave Imaging Applications. Materials, 8, 392-407. https://doi.org/10.3390/ma8020392

[12] Wu, B., Ji, Y. and Fang, G. (2009) Design and Measurement of Compact Tapered Slot Antenna for UWB Microwave Imaging Radar. 2009 9th International Conference on Electronic Measurement \& Instruments, Beijing, 16-19 August 2009, 226-229. https://doi.org/10.1109/ICEMI.2009.5274613

[13] Tayel, M.B., Abouelnaga, T.G. and Desouky, A.F. (2016) A Coaxial-to-CPW Transition for Microwave Breast Cancer Detection Antennas. IOSR Journal of Electrical and Electronics Engineering (IOSR-JEEE), 11, $42-53$. https://doi.org/10.9790/1676-1105024253

[14] Garg, R., Bahl, I. and Bozzi, M. (2013) Microstrip Lines and Slotlines. Artech House, London.

[15] Islam, M.T., Islam, M., Samsuzzaman, M., Faruque, M.R.I. and Misran, N. (2015) A Negative Index Metamaterial-Inspired UWB Antenna with an Integration of Complementary SRR and CLS Unit Cells for Microwave Imaging Sensor Applications. Sensors, 15, 11601-11627. https://doi.org/10.3390/s150511601

[16] Rusni, I.M., Ismail, A., Alhawari, A.R.H., Hamidon, M.N. and Yusof, N.A. (2014) An Aligned-Gap and Centered-Gap Rectangular Multiple Split Ring Resonator for Dielectric Sensing Applications. Sensors, 14, 13134-13148. https://doi.org/10.3390/s140713134

[17] Dardeer, O., Abouelnaga, T., Mohra, A. and Elhennawy, H. (2017) Compact UWB Power Divider, Analysis and Design. Journal of Electromagnetic Analysis and Applications, 9, 9-21. https://doi.org/10.4236/jemaa.2017.92002 